\title{
The causes, sequelae and attempts at prevention of cervical spine injuries in Poland
}

\author{
J E Kiwerski MD ScD
}

\author{
The Metropolitan Rehabilitation Center, The Rehabilitation Clinic of the Medical \\ Academy in Warsaw, 05-511 Konstancin, Wierzejewskiego 12, Poland.
}

\begin{abstract}
There are certain differences between the causes of spinal injuries in Poland and in the developed countries of the West. The most common causes of injuries to the cervical spine in Poland are: falls from a horse-cart, diving into shallow water and automobile accidents. This paper presents an analysis of the causes of cervical spine injuries in a series of 1937 patients treated at the Spinal Cord Injury Department of the Metropolitan Rehabilitation Center in Konstancin, Poland, in the years between 1965 and 1991, admitted to hospital within the first hours or days after spinal injury. The relations between the mechanism of injury and the cause of injury, as well as the neurological sequelae of the injuries, are analysed.
\end{abstract}

Keywords: cervical spinal cord injury; neurological outcomes.

\section{Introduction}

There are certain differences between the causes of spinal injuries in Poland and in the developed countries of the West. ${ }^{1-6}$ Poland is to a large extent an agricultural country, with a large number of small farms and rather poorly developed agricultural engineering, although in recent years there has been some integration of land property and small farms and some advancement in the farming techniques. But it is still the horsedriven vehicle, the horse cart, which is the basic means of transport of hay, corn and other farm produce on many farms, falls from which account for the largest percentage of spinal cord injury (SCI). The motorcycle is another very popular means of transport in the country and a common cause of SCI; the number of cars is increasing gradually.

A frequent cause of injury to the spine sustained by young people is diving into shallow water. ${ }^{7}$ There are insufficient numbers of swimming pools in Poland, and therefore the natural water reservoirs, such as rivers and lakes, are often used even although they do not meet the basic safety requirements.

This paper presents an analysis of the causes of cervical spine injuries in a series of
1937 patients treated at the Spinal Cord Injury Department of the Metropolitan Rehabilitation Center in Konstancin, Poland, in the years between 1965 and 1991, admitted to hospital within the first hours or days after spinal injury. The relations between the mechanism of injury and the cause of injury, as well as the neurological sequelae of the injuries, are analysed.

\section{Causes of spinal injury}

Table I presents the commonest causes of cervical spine injuries with regard to the community background of the patients (urban vs rural areas). The overall commonest causes of injury in our material were: falls from a horse-cart (about $25 \%$ of cases), diving (about 20\%) and automobile accidents $(13.5 \%)$. The ratios differ, however, according to the community background. Among patients from urban areas, the single most common cause of injury to the cervical spine was diving (over $30 \%$ of cases), followed by automobile accidents $(24 \%)$ and falls from low heights $(10 \%)$, supplemented by quite a number of falls from stairs $(5.5 \%)$. Among patients from rural areas, the dominant causes of injury were falls from a horse-cart, accounting for 
Table I The causes of cervical spine injuries

\begin{tabular}{|c|c|c|c|c|c|c|}
\hline \multirow[t]{2}{*}{ Cause of injury } & \multicolumn{2}{|c|}{ Urban areas } & \multicolumn{2}{|c|}{ Rural areas } & \multicolumn{2}{|c|}{ Total } \\
\hline & No & $\%$ & No & $\%$ & No & $\%$ \\
\hline \multicolumn{7}{|c|}{ Falls from a height } \\
\hline Horse-cart & 23 & 2.6 & 447 & 42.0 & 470 & 24.3 \\
\hline Roof & 6 & 0.7 & 49 & 4.6 & 55 & 2.8 \\
\hline Ladder & 21 & 2.4 & 85 & 8.0 & 106 & 5.5 \\
\hline Stairs & 48 & 5.5 & 15 & 1.4 & 63 & 3.2 \\
\hline Scaffolding & 27 & 3.1 & 7 & 0.7 & 34 & 1.8 \\
\hline Tree & 17 & 1.9 & 33 & 3.1 & 50 & 2.6 \\
\hline Suicidal & 12 & 1.4 & 3 & 0.3 & 15 & 0.8 \\
\hline Small height & 86 & 9.9 & 47 & 4.4 & 133 & 6.9 \\
\hline \multicolumn{7}{|l|}{ Other falls } \\
\hline Great height & 23 & 2.6 & 12 & 1.1 & 35 & 1.8 \\
\hline Diving & 265 & 30.4 & 118 & 11.1 & 383 & 19.8 \\
\hline \multicolumn{7}{|l|}{ Road accidents } \\
\hline Automobile & 210 & 24.1 & 52 & 4.9 & 262 & 13.5 \\
\hline Motorcycle & 22 & 2.5 & 52 & 4.9 & 74 & 3.8 \\
\hline Bicycle & 13 & 1.5 & 25 & 2.4 & 38 & 2.0 \\
\hline Pedestrian & 30 & 3.4 & 46 & 4.3 & 76 & 3.9 \\
\hline Other & 8 & 0.9 & 18 & 1.7 & 26 & 1.3 \\
\hline \multicolumn{7}{|c|}{ Compression by a heavy } \\
\hline object & 28 & 3.2 & 27 & 2.5 & 55 & 2.8 \\
\hline Other causes & 34 & 3.9 & 28 & 2.6 & 62 & 3.2 \\
\hline Total & 973 & 100.0 & 1064 & 100.0 & 1937 & 100.0 \\
\hline
\end{tabular}

as many as $42 \%$ of cases, followed much less frequently by diving accidents $(11 \%)$, and falls from a ladder $(8 \%)$. Table II shows the age distribution of the patients. The majority sustained the injury in the most active period of their lives, between 20 and 60 years of age (over $64 \%$ ). The fewest were in the youngest age group, up to 20 years $(15 \%)$. Certain causes of injury are age related: falls from a horse-cart more often led to an injury in older people $(46 \%$ of patients were aged over 60 years, only $14 \%$ were aged up to 40 years); the situation was similar in the group of injuries caused by falls from a ladder, where $44 \%$ of patients were aged over 60 years, and only $14 \%$ were under 40. Pedestrian accidents also more often involved older individuals $(77 \%$ of the patients were over 40 and $33 \%$ over 60 years of age). Spinal fractures following suicidal jumps were only found in young people, aged up to 40 years. Young individuals prevailed also among the victims of falls from a tree (64\% were aged up to 40 years), falls from great heights $(77 \%$ were aged up to 40 years), diving ( $47 \%$ were aged up to 20 years, $97 \%$ up to 40 years) and automobile accidents (over $86 \%$ of patients were aged up to 40 years).

Table III shows the time (the quarter of the year) when the injury was sustained. Fewest accidents occurred in the first 3 months of the year (about $9 \%$ ), while the third quarter of the year was the period for the highest incidence of traumas $(61 \%$ of all the injuries to the cervical spine). The relation with summertime (the third quarter of the year) is particularly prominent in patients who have fallen from a horse-cart (over $72 \%$ of traumas took place within the third quarter), falls from a ladder (56\%), tree $(84 \%)$, great heights $(57 \%)$, diving $(88 \%)$, automobile $(55 \%)$ and other road accidents $(58 \%)$. 
Table II Age of patients

\begin{tabular}{|c|c|c|c|c|c|c|c|c|c|}
\hline \multirow[t]{2}{*}{ Cause of injury } & \multicolumn{8}{|c|}{ Age of patients } & \multirow[b]{2}{*}{ Total } \\
\hline & Up to 20 & $\%$ & $21-40$ & $\%$ & $41-60$ & $\%$ & Over 60 & $\%$ & \\
\hline \multicolumn{10}{|c|}{ Falls from a height } \\
\hline Horse-cart & 3 & 1.0 & 64 & 9.4 & 188 & 33.4 & 215 & 53.1 & 470 \\
\hline Roof & - & - & 23 & 3.4 & 20 & 3.6 & 12 & 3.0 & 55 \\
\hline Ladder & - & - & 15 & 2.2 & 44 & 7.8 & 47 & 11.6 & 106 \\
\hline Stairs & 2 & 0.7 & 16 & 2.3 & 28 & 5.0 & 17 & 4.2 & 63 \\
\hline Scaffolding & - & - & 14 & 2.0 & 17 & 3.0 & 3 & 0.7 & 34 \\
\hline Tree & 10 & 3.5 & 22 & 3.2 & 13 & 2.3 & 5 & 1.2 & 50 \\
\hline Suicidal & 3 & 1.0 & 12 & 1.8 & - & - & - & - & 15 \\
\hline Small height & 15 & 5.2 & 40 & 5.9 & 45 & 8.0 & 33 & 8.2 & 133 \\
\hline \multicolumn{10}{|l|}{ Other falls } \\
\hline Great height & 3 & 1.0 & 24 & 3.5 & 8 & 1.4 & - & - & 35 \\
\hline Diving & 179 & 62.0 & 194 & 28.5 & 10 & 1.8 & - & - & 383 \\
\hline \multicolumn{10}{|l|}{ Road accidents } \\
\hline Automobile & 23 & 8.0 & 133 & 19.6 & 84 & 14.9 & 22 & 5.4 & 262 \\
\hline Motorcycle & 24 & 8.3 & 40 & 5.9 & 9 & 1.6 & 1 & 0.2 & 74 \\
\hline Bicycle & 7 & 2.4 & 12 & 1.8 & 15 & 2.6 & 4 & 1.0 & 38 \\
\hline Pedestrian & 5 & 1.7 & 12 & 1.8 & 34 & 6.0 & 25 & 6.2 & 76 \\
\hline Other & 2 & 0.7 & 10 & 1.5 & 10 & 1.8 & 4 & 1.0 & 26 \\
\hline \multicolumn{2}{|c|}{ Compression by a heavy } & 2.1 & 18 & 2.6 & 20 & 3.6 & 11 & 2.7 & 55 \\
\hline Other causes & 7 & 2.4 & 31 & 4.6 & 18 & 3.2 & 6 & 1.5 & 62 \\
\hline Total & 289 & 100 & 680 & 100 & 563 & 100 & 405 & 100 & 1937 \\
\hline
\end{tabular}

\section{Mechanism of the spinal injury}

The mechanism of the spinal injury was assessed on the basis of the initial radiographs and anamnesis data. In accordance with earlier observations, the injuries from a flexion mechanism are divided into fractures and dislocations, ${ }^{8}$ while compression injuries are either fractures or crush injuries. ${ }^{9}$

Table IV shows the mechanism of spinal injury in relation to the cause of injury. For classification, all falls from a height are grouped together, except falls from a horsecart as being the most frequent; and similarly, road accidents are presented here as one group with the exception of the most frequent automobile accidents.

In general, the commonest mechanism of injury was flexion ( $48 \%$ of all cases) with a prevalence of a flexion dislocation (35\%). Injuries from an extension mechanism $(26 \%)$ were of approximately the same incidence as were injuries from a compression mechanism. The incidence of particular mechanisms of injury was to some extent dependent on the cause of injury. Among the injuries following falls from a horse-cart, flexion dislocations were in fact dominant $(45 \%)$, but injuries from an extension mechanism were not much less frequent $(35 \%)$. Similarly, among patients whose trauma was caused by other falls from a height, both kinds of injuries were equally frequent $(33 \%)$. Injuries following diving were mainly from a compression mechanism (61\% of cases), with a prevalence of crush fractures $(39 \%)$ which were relatively rare in the other groups of trauma.

Automobile accidents most often resulted in injuries from a flexion mechanism $(62 \%)$ with a prevalence of dislocations (46\%). In other road accidents, however, injuries from an extension mechanism were more frequent $(40 \%)$ than were flexion dislocations $(34 \%)$, which were second in incidence. Flexion dislocations also prevailed among injuries due to compression by heavy objects 
Table III Time (quarter of the year) of spinal injury

\begin{tabular}{|c|c|c|c|c|c|c|c|c|c|c|}
\hline \multirow[t]{3}{*}{ Cause of injury } & \multicolumn{8}{|c|}{ Quarter of the year } & & \\
\hline & \multicolumn{2}{|c|}{ I } & \multicolumn{2}{|c|}{ II } & \multicolumn{2}{|c|}{ III } & \multicolumn{2}{|c|}{ IV } & \multicolumn{2}{|c|}{ Total } \\
\hline & No & $\%$ & No & $\%$ & No & $\%$ & No & $\%$ & No & $\%$ \\
\hline \multicolumn{11}{|c|}{ Falls from a height } \\
\hline Horse-cart & 22 & 4.7 & 88 & 18.7 & 340 & 72.3 & 20 & 4.3 & 470 & 100 \\
\hline Roof & 3 & 5.5 & 7 & 12.7 & 24 & 43.6 & 21 & 38.2 & 55 & 100 \\
\hline Ladder & 12 & 11.3 & 17 & 16.0 & 59 & 55.7 & 18 & 17.0 & 106 & 100 \\
\hline Stairs & 6 & 9.5 & 20 & 31.7 & 19 & 28.6 & 18 & 28.6 & 63 & 100 \\
\hline Scaffolding & 4 & 11.8 & 11 & 32.3 & 14 & 41.2 & 5 & 14.7 & 34 & 100 \\
\hline Tree & - & - & 5 & 10.0 & 42 & 84.0 & 3 & 6.0 & 50 & 100 \\
\hline Suicidal & 2 & 13.3 & 4 & 26.7 & 6 & 40.0 & 3 & 20.0 & 15 & 100 \\
\hline \multicolumn{11}{|l|}{ Other falls } \\
\hline Small height & 32 & 24.0 & 30 & 22.6 & 41 & 30.8 & 30 & 22.6 & 133 & 100 \\
\hline Great height & 4 & 11.4 & 8 & 22.9 & 20 & 57.1 & 3 & 8.6 & 35 & 100 \\
\hline Diving & 3 & 0.8 & 42 & 11.0 & 336 & 87.7 & 2 & 0.5 & 383 & 100 \\
\hline \multicolumn{11}{|l|}{ Road accidents } \\
\hline Automobile & 38 & 14.5 & 37 & 14.1 & 145 & 55.4 & 42 & 16.0 & 262 & 100 \\
\hline Motorcycle & 1 & 1.4 & 38 & 51.4 & 30 & 40.5 & 5 & 6.7 & 74 & 100 \\
\hline Bicycle & - & - & 16 & 42.1 & 18 & 47.4 & 4 & 10.5 & 38 & 100 \\
\hline Pedestrian & 25 & 32.9 & 11 & 14.5 & 18 & 23.7 & 22 & 28.9 & 76 & 100 \\
\hline Other & 1 & 3.9 & 3 & 11.5 & 15 & 57.7 & 7 & 26.9 & 26 & 100 \\
\hline \multicolumn{2}{|c|}{ Compression by a heavy } & 10.9 & 18 & 32.7 & 19 & 34.6 & 12 & 21.8 & 55 & 100 \\
\hline Other causes & 11 & 17.7 & 12 & 19.4 & 27 & 43.5 & 12 & 19.4 & 62 & 100 \\
\hline Total & 170 & 8.8 & 367 & 18.9 & 1173 & 60.6 & 227 & 11.7 & 1937 & 100 \\
\hline
\end{tabular}

$(52 \%)$, and in the group of injuries due to other causes $(37 \%)$.

\section{Neurological sequelae of the cervical spine injury}

Table $\mathrm{V}$ presents the degree of spinal cord injury assessed on admission in relation to the most common causes of injury. The degree of the damage to the spinal cord is assessed according to a modification of the classification of Frankel et al ${ }^{10}$ ie complete, three incomplete groups ${ }^{8,11}$ and essentially normal. The injury is assessed as complete if there is motor paralysis and absence of all sensation below the level of the spinal cord lesion. Incomplete injuries are divided into three groups: group 1-motor paralysis with at least traceable deep sensation preserved in the feet; group 2-severe tetraparesis (or hemiparesis); group 3-pareses of lesser severity, with paretic muscle strength over $3^{\circ}$ on the MRC scale.
In total, $39 \%$ of the patients had the signs and symptoms of a complete spinal cord injury on admission. Over $50 \%$ of patients had tetraplegia (including group 1 of the incomplete injuries). Only $10 \%$ had no significant neurological deficits (with the possibility of paraesthesiae, numbness, and radiculalgia).

The most serious sequelae were noted in patients with injuries caused by diving. As many as $64 \%$ of them had tetraplegia, and $50 \%$ had a complete spinal cord injury on admission. Eight percent of the victims of diving had no significant neurological deficits. Much better neurologically were the patients injured in automobile accidents, $39 \%$ of these patients having a complete spinal cord lesions and $15 \%$ having no significant neurological deficits. More serious damage to the spinal cord was found in victims of other road accidents, particularly motorcycle and pedestrian accidents. Among these patients, $55 \%$ had motor 


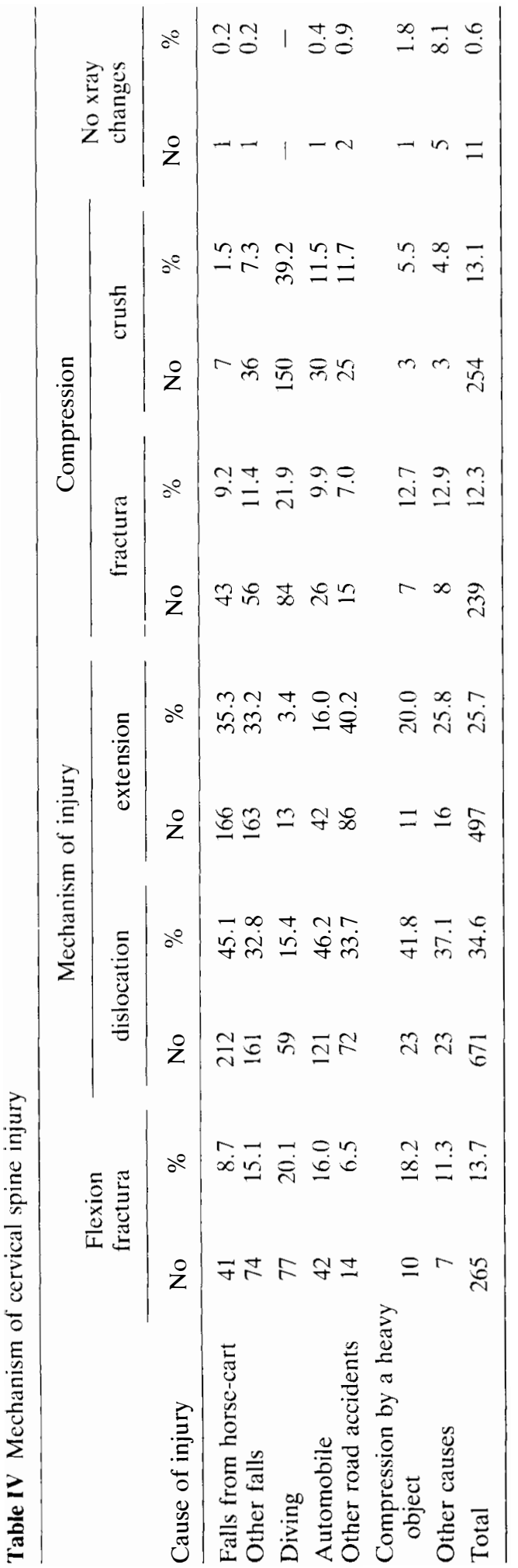

paralysis $(42 \%$ had complete spinal cord lesions) and only $8 \%$ had no significant neurological disorder.

Similar neurological sequelae were observed in patients with spinal injuries following falls from a horse-cart and other falls from a height. In both of these groups, complete spinal cord injury was found in $34 \%$ of cases, while about $10 \%$ of patients in both groups had no significant neurological deficit.

\section{Attempts at prevention of cervical spine injuries}

The most common causes of injuries to the cervical spine in Poland are: falls from a horse-cart; diving into shallow water; and road accidents, particularly those involving automobiles. Altogether, these causes account for nearly $70 \%$ of the cervical spine injuries. Therefore the preventive measures focus on warning against the threatening dangers.

In the spring and summer, a special campaign is run in the mass media, especially radio and TV programmes for young people, to warn of and heighten the awareness of the possible consequences of haphazard diving into unfamiliar or shallow water reservoirs, on unguarded beaches. The majority of spinal injuries due to diving take place at the end of June and the beginning of holidays for students of all education levels.

Falls from a horse-cart resulting in spinal injuries are also most frequent in the summertime, during the harvesting and hay gathering. Hopefully, some improvement in this respect may be brought about by the warning campaign in the press and programmes for farmers pointing to the risks connected with placing the carter's seat on the top of the heavily loaded wagons of hay or corn. On the other hand, the modernisation of farming techniques and gradual replacement of the horse-driven vehicles by modern machines will further reduce the numbers of this kind of accident.

Regretfully, the frequent radio and TV announcements reporting on the worsening driving conditions in particular regions of the country and on the tragic consequences 
Table V Initial neurological state

\begin{tabular}{|c|c|c|c|c|c|c|c|c|c|c|c|c|}
\hline \multirow[b]{4}{*}{ Cause of injury } & \multicolumn{8}{|c|}{ Degree of spinal cord injury } & \multirow{3}{*}{\multicolumn{2}{|c|}{$\begin{array}{c}\text { Without } \\
\text { neurological } \\
\text { deficit }\end{array}$}} & & \\
\hline & \multirow{2}{*}{\multicolumn{2}{|c|}{ Complete }} & \multicolumn{6}{|c|}{ Incomplete } & & & & \\
\hline & & & \multicolumn{2}{|c|}{1} & \multicolumn{2}{|c|}{2} & \multicolumn{2}{|c|}{3} & & & \multicolumn{2}{|c|}{ Total } \\
\hline & No & $\%$ & No & $\%$ & No & $\%$ & No & $\%$ & No & $\%$ & No & $\%$ \\
\hline Falls from horse-cart & 162 & 34.5 & 52 & 11.1 & 107 & 22.7 & 102 & 21.7 & 47 & 10.0 & 470 & 100 \\
\hline Other falls & 168 & 34.2 & 48 & 9.8 & 96 & 19.5 & 125 & 25.5 & 54 & 11.0 & 491 & 100 \\
\hline Diving & 192 & 50.1 & 54 & 14.1 & 47 & 12.3 & 60 & 15.7 & 30 & 7.8 & 383 & 100 \\
\hline Automobile & 102 & 38.9 & 29 & 11.1 & 33 & 12.6 & 60 & 22.9 & 38 & 14.5 & 262 & 100 \\
\hline Other road accidents & 89 & 41.6 & 28 & 13.1 & 35 & 16.4 & 45 & 21.0 & 17 & 7.9 & 214 & 100 \\
\hline $\begin{array}{l}\text { Compression by a heavy } \\
\text { object }\end{array}$ & 21 & 38.2 & 10 & 18.2 & 10 & 18.2 & 11 & 20.0 & 3 & 5.4 & 55 & 100 \\
\hline Other causes & 20 & 32.3 & 3 & 4.8 & 13 & 21 & 14 & 22.6 & 12 & 19.3 & 62 & 100 \\
\hline Total & 754 & 38.9 & 224 & 11.6 & 341 & 17.6 & 417 & 21.5 & 201 & 10.4 & 1937 & 100 \\
\hline
\end{tabular}


of road accidents are disappointingly ineffective. The growing number of motor vehicles on the road, combined with the bravado and carelessness on the part of the drivers, frequently augmented by imbibing alcohol, are factors that contribute to the gradual increase in the number of accidents and the subsequent injuries to the spine. Hopefully, the recent introduction of new road regulations making it compulsory to drive with the headlights on during the autumn and winter months, and the tightened sanctions against unruly or inebriated drivers will bring about a change and decrease the number of road accidents and their tragic consequences.

\section{Conclusions}

1 The commonest causes of injuries to the cervical spine in Poland are: falls from a horse-cart, diving into shallow water and road accidents, especially those involving cars.

2 The causes of the different aetiologies in the urban areas are: diving $(30 \%$ of cases), automobile accidents (24\%), and falls from low heights $(10 \%)$. In the rural areas the dominant causes are falls from a horse-cart $(42 \%)$, diving $(11 \%)$ and falls from a ladder $(8 \%)$.

3 Injuries to the cervical spine are most often sustained in the summertime due to the high incidence of falls from a horsecart, tree, diving and road accidents during that period of time.

4 The neurological sequelae of these injuries are severe. On admission over $50 \%$ of the patients presented with tetraplegia.

5 The preventive measures focus on campaigns run in the mass media to warn against the consequences of the most frequent injuries.

\section{References}

1 Biering-Sørensen F, Pedersen W, Clausen S (1990) Epidemiology of spinal cord lesions in Denmark. Paraplegia 28: 105-118.

2 Bracken MB, Freeman DH, Hellenbrand K (1981) Incidence of acute traumatic spinal cord injury in the United States. Am J Epidemiol 13: 615-622.

3 Garcia-Reneses J, Herruzo-Cobrera R, Martinez-Moreno M (1991) Epidemiological study of spinal cord injury in Spain. Paraplegia 29: 180-190.

4 Kewalramani LL, Kraus JF, Sterling HM (1980) Acute spinal cord lesions. Epidemiology and clinical features. Paraplegia 18: 206-214.

5 Korning W, Frowein AR, Firsching E (1987) Epidemiology of spinal cord injuries. In: Harris PH, editor. Thoracic and Lumbar Spine and Spinal Cord Injuries. Springer, Wien: 1-15.

6 Minaire P, Castanier M, Retcoll G (1978) Epidemiology of spinal cord injury in the Rhone-Alpesregion, France. Paraplegia 16: 76-88.

7 Kiwerski J (1980) Cervical spine injuries caused by diving into water. Paraplegia 18: 37-41.

8 Kiwerski J (1991) The influence of the mechanism of cervical spine injury on the degree of the spinal cord lesion. Paraplegia 29: 531-536.

9 Kiwerski J (1991) Differentiation of spinal damage through compression mechanism. Paraplegia 29: 411-418.

10 Frankel H, Hancock D, Hyslop G, Melzak J, Michaelis LS, Ungar GH et al (1969) The value of postural reduction in the initial management of closed injuries to the spine with paraplegia and tetraplegia. Paraplegia 7: 179-192.

11 Haftek J, Rudnicki S, Kiwerski J (1968) Acute trauma of cervical segment of the spinal cord. In: M Weiss, editor. Compensation of Spinal Cord Function. PZWL, Warsaw: 75-86. 